\title{
Improving of Gelling Capacity of Cooked Crab Meat Proteins
}

\author{
Gabriela Nallely Trejo-Díaz ${ }^{1,2}$, Miguel Ángel Martínez-Maldonado ${ }^{3}$, \\ Rocío M. Uresti-Marin ${ }^{1 *}$, Gonzalo Velazquez ${ }^{4}$ and José Alberto Ramírez ${ }^{1}$ \\ ${ }^{1}$ Unidad Académica de Trabajo Social y Ciencias para las Humanidades, Universidad Autónoma de Tamaulipas, Ciudad Vic, \\ Mexico, ${ }^{2}$ Facultad de Nutrición, Universidad de Ciencias y Artes de Chiapas, Tuxtla Gutiérrez, Mexico, ${ }^{3}$ Centro de Física \\ Aplicada y Tecnología Avanzada, Universidad Nacional Autónoma de México, Querétaro, Mexico, ${ }^{4}$ Instituto Politécnico \\ Nacional-Centro de Investigación en Ciencia Aplicada y Tecnología Avanzada, Unidad Querétaro, Querétaro, Mexico
}

\section{OPEN ACCESS}

Edited by:

Juliana Morales-Castro, Durango Institute of

Technology, Mexico

Reviewed by:

Chayon Goswami,

Bangladesh Agricultural

University, Bangladesh Alexandru Rusu,

Biozoon, Germany

*Correspondence:

Rocío M. Uresti-Marín

ruresti@docentes.uat.edu.mx

Specialty section:

This article was submitted to

Nutrition and Sustainable Diets,

a section of the journal

Frontiers in Nutrition

Received: 03 March 2021

Accepted: 02 July 2021

Published: 30 September 2021

Citation:

Trejo-Díaz GN, Martínez-Maldonado MÁ, Uresti-Marín RM, Velazquez $G$ and Ramirez JA (2021) Improving of Gelling Capacity of Cooked Crab Meat Proteins. Front. Nutr. 8:675362. doi: 10.3389/fnut.2021.675362
Cooked crab meat subjected to a cutting process can aggregate again, forming weak gels. The objective of this work was to determine the effect of two mixing methods, combined with the addition of the microbial enzyme TGase (MTGase) on the mechanical and functional properties of gels from washed or unwashed blue crab (Callinectes sapidus) meat. Live crabs were obtained from Laguna Madre, Tamaulipas, Mexico, and cooked at $120^{\circ} \mathrm{C}$ for 20 min before hand-picking the meat from the shell. Cooked meat was processed by mixing and cut at temperatures of 25 or $60^{\circ} \mathrm{C}$, without (control) or $0.5 \%$ of MTGase. Then cooked at $90^{\circ} \mathrm{C}$ for $15 \mathrm{~min}$. Changes in texture profile analysis, percentage of extractable water, and color were evaluated. The mixing method at $60^{\circ} \mathrm{C}$ allowed increasing the textural properties of the gels, and the addition of MTGase significantly improved the mechanical properties. The results allowed stablishing a viable technique to obtain restructured gels from cooked crab meat with no need to extract the soluble compounds responsible for their distinctive odor and taste which often affect the mechanical properties.

Keywords: crab meat, microbial transglutaminase, mixing, cutting, gelling

\section{INTRODUCTION}

The crabs belong to the brachyury group (brachyura), as they are decapod crustaceans, and include about 4,500 species (1). They are the livelihood of high demand and commercial value fisheries worldwide (2).

Crabs are immersed in water at boiling or retorting temperature, to facilitate the manual extraction and separation of meat. Each anatomical section has different economic value in the international market. This cooking process limits the production of restructured crab products, as cooked meat from vertebrates, and invertebrates do not usually form gels (3).

Obtaining restructured products from cuts of meat from vertebrates and invertebrates requires solubilizing the native muscle proteins with salt, homogenizing, formatting, and cooking to obtain the desired shape (4). Meat must not have been previously heated or frozen to obtain quality products (5).

The frozen Johan crab cooked meat (Cancer borealis) can form weak gels if washed with cold water (a technique used to obtain surimi) and does not require the use of salt to gel when incubated at $35^{\circ} \mathrm{C}$ for $30 \mathrm{~min}$ before cooking it to $90^{\circ} \mathrm{C}$ for $30 \mathrm{~min}(6,7)$. The authors did not mention the effect that washing cooked crab meat has on taste as this process removes water-soluble compounds associated with the taste, smell, and color of fish meat and should have the same effect on crab meat. 
Blue crab meat (Callinectes sapidus) cooked at $120^{\circ} \mathrm{C}$ had better textural characteristics than meat obtained by cooking at $50-70^{\circ} \mathrm{C}$, suggesting that the gelling mechanism of cooked meat is associated with the unfolding of previously thermally aggregated proteins (8). Adding microbial transglutaminase improved the properties of cooked crab gels requiring only one cold water washing cycle to obtain restructured products $(9,10)$.

The use of high hydrostatic pressures at $400 \mathrm{MPa}$ for $5 \mathrm{~min}$ improved the mechanical properties of thermally induced fish gels; however, after raising the pressure level to $600 \mathrm{MPa}$, the increase in texture was less (11). In gels obtained from cooked crab meat, a favorable effect of the pressure was observed on the textural properties when the gels were pressurized to $100 \mathrm{MPa}$. This effect was less important when pressures of 300 or $600 \mathrm{MPa}$ were used (12).

Studies on cooked crab meat have allowed developing processes to obtain gels from muscle proteins shredded to fine grain. Still, these products have a weak texture, compared to commercial restructured products. The objective of this work was to develop a process that would improve the mechanical properties of gels, considering the particle size of the matter used in the process and the effect of adding transglutaminase to washed or unwashed crab meat.

\section{MATERIALS AND METHODS}

\section{Crab Meat}

The blue crab was captured in Laguna Madre, in the vicinity of the town Carboneras, located in the municipality of San Fernando, Tamaulipas, Mexico. The crabs were transported to the facilities of a processing plant located in the city of San Fernando, Tamaulipas, Mexico, within the first $4 \mathrm{~h}$ after its capture. The blue crab was processed at $120^{\circ} \mathrm{C}$ for $20 \mathrm{~min}$ in a commercial autoclave and the meat was removed from the shell manually on the production line. The crab meat was stored in plastic containers with abundant ice and transported to the lab for further processing.

\section{Washing Crab Meat}

The cooked crab meat was processed between 4 and $6 \mathrm{~h}$ after being received in the laboratory. The meat underwent a washing cycle with cold water below $4^{\circ} \mathrm{C}$, in a ratio of $3: 1$ water/meat, stirring gently for $7 \mathrm{~min}$, and letting the mixture rest for $10 \mathrm{~min}$ before draining. A commercial fabric was used to manually extract the excess water.

\section{Production of Crab Meat Gels}

Cooked crab meat gels were obtained from unwashed or with a wash cycle meat. Two processes were used: mixing or cutting. The mixing process was carried out using a commercial 6speed blender (Black \& Decker, model MX3200B, Mexico). The ingredients were dispersed homogeneously into the meat for $3 \mathrm{~min}$, at speed 3 , using the beater blades included in the equipment. The microbial TGase (MTGase, Active TG-TI, Ajinomoto USA, Inc., Teaneck, NJ) was added in powder, at $0.5 \% \mathrm{w} / \mathrm{w}$, and two mixing temperatures were used: 25 or $60^{\circ} \mathrm{C}$. An MTGase-free control gel was obtained for each treatment.
To prepare gels by the chopping process, a Hamilton Beach cutter of $0.7 \mathrm{~L}$ (model 72860, USA) was used, cutting the samples for $1 \mathrm{~min}$ at 25 or $60^{\circ} \mathrm{C}$. MTGase was added at $0.5 \% \mathrm{w} / \mathrm{w}$. Control gels were obtained without MTGase. Mixed or cut pastes were introduced into stainless steel tubes $(1.8 \mathrm{~cm}$ inner diameter, $17.7 \mathrm{~cm}$ in length). The steel tubes were closed with threaded plugs before incubation at $60^{\circ} \mathrm{C}$ for $30 \mathrm{~min}$, followed by a water immersion at $90^{\circ} \mathrm{C}$ for $15 \mathrm{~min}$. After cooking, the tubes were placed in a cold-water bath $\left(5^{\circ} \mathrm{C}\right)$ for $30 \mathrm{~min}$ and stored for $10 \mathrm{~h}$ at $4^{\circ} \mathrm{C}$.

\section{Texture Profile Analysis}

The mechanical properties were determined following the method described by Martínez et al. (8), using a Stable Micro Systems Texturometer (Model TAXT2i, Vienna Court, England, UK). The size of the gel samples was $1.87 \mathrm{~cm}$ in diameter and $3 \mathrm{~cm}$ in length and equilibrated at room temperature by $30 \mathrm{~min}$, in plastic bags, to avoid dehydration before measurements. Texture profile analysis (TPA) was performed by compressing samples at $75 \%$ of their initial height. A cylindrical aluminum probe $(\mathrm{P} / 50)$ with a $50 \mathrm{~mm}$ diameter and a crosshead speed of 60 $\mathrm{mm} / \mathrm{min}$ were used. The hardness, cohesiveness, springiness, and chewiness values were reported. Six samples were analyzed for each treatment.

\section{Color}

A precise color reader portable colorimeter (HP 2000, Guangdong, China) calibrated with a white and black tile, identified as standards, was used to assess color in gels. Six replicates were performed on each sample (six control samples and six samples with a washing cycle for mixed or cut pastes). The parameters obtained by the instrument $\left(\mathrm{L}^{*}, \mathrm{a}^{*}\right.$, and $\left.\mathrm{b}^{*}\right)$, were used to calculate the values of $\mathrm{C}^{*}$ and $\mathrm{H}^{*}$.

\section{Expressible Water}

The expressible water content was determined by centrifugation. Restructured samples $(5 \mathrm{~g})$ were wrapped in Whatman No. 1 paper, with a size of $15 \times 15 \mathrm{~cm}$. A triplicated determination was made for each of the treatments. The initial weight of each sample was recorded. The wrapped samples were placed in a centrifuge (Hettich Zentrifugen Rotofix 32-A, Tuttlingen, Germany) at 1000 rpm for $5 \mathrm{~min}$. The final weight of the sample was recorded, and the removable water was determined.

$$
\text { Expressible water }=\frac{\text { Initial weight }- \text { final weight }}{{ }^{*}} 100
$$

\section{Statistical Analysis}

A multifactorial analysis of variance was carried out using Statgraphics 5 software (Manugistics, Inc., Rockville, MD). Differences between mean values were established using the least significant difference (LSD) multiple range test and they were considered significant when $p<0.05$.

\section{RESULTS AND DISCUSSION}

The effect of the particle size (mixing or cutting) of crab meat on the textural properties of gels was analyzed. The structure of the 

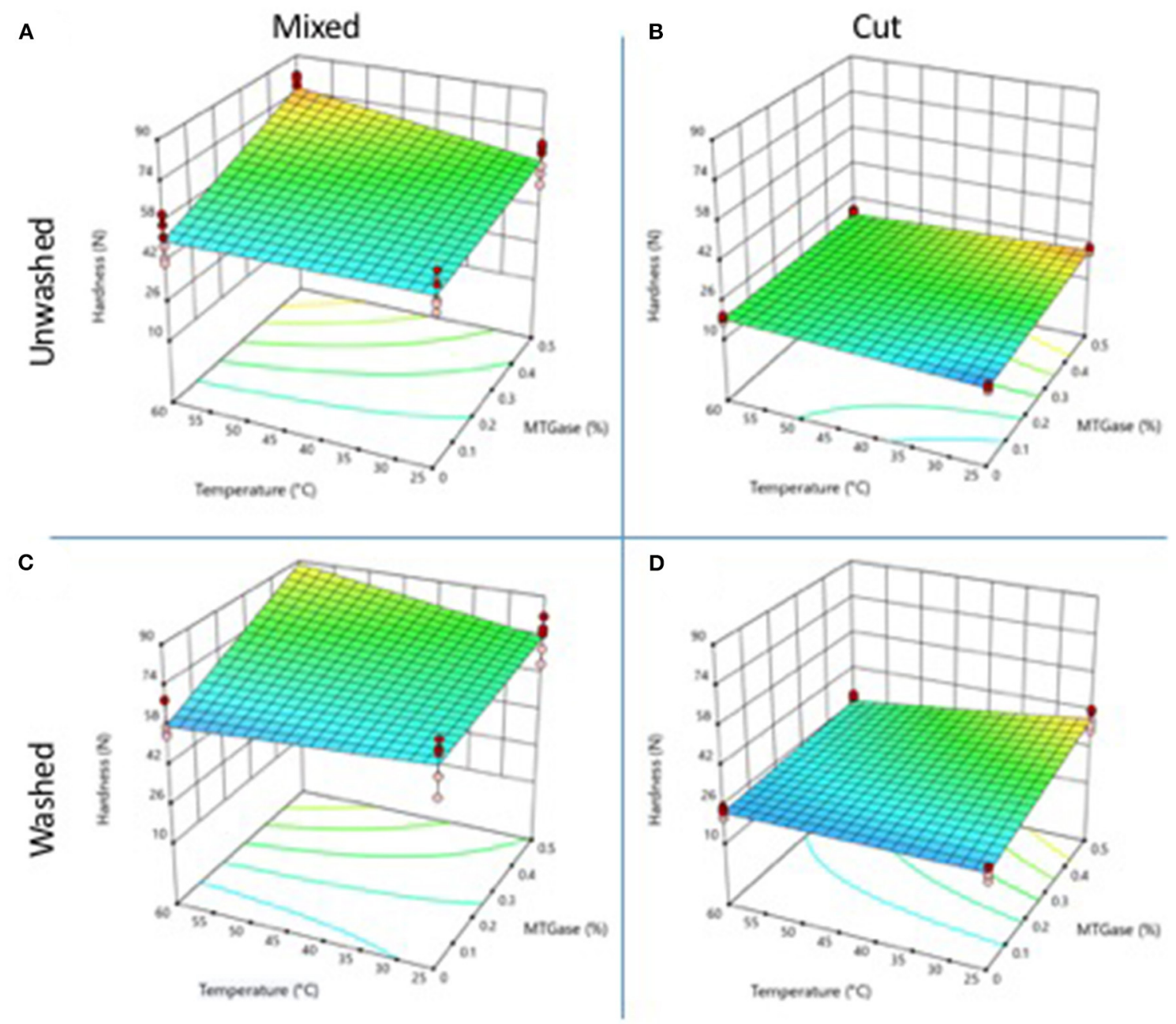

FIGURE 1 | Changes in gel hardness properties as a function of the type and temperature mixing method, washing of the cooked meat, and adding of MTGase. (A) Mixed-unwashed samples, (B) Cut-unwashed samples, (C) Mixed-washed samples, and (D) Cut-washed samples.

fibers remained unaltered in the mixing batch, meanwhile, the other batch underwent a considerable reduction by cutting. In both cases, no salt was added, as it has been reported that it is not required to solubilize proteins when obtaining crab gels (7). This property suggests that, unlike other restructured meat products, shredding may not be required either to obtain gels from crab meat. Changes induced by adding microbial transglutaminase enzyme, subjecting meat to cold water washes, and mixing type and temperature were also evaluated.

\section{Hardness}

Figure 1A shows the behavior of the hardness values of gels obtained from unwashed crab meat. In control gels, without the addition of microbial TGase, it was observed that the mixing treatment allowed obtaining gels with hardness values of 51.80 and $50.95 \mathrm{~N}$ at 25 and $60^{\circ} \mathrm{C}$, respectively, significantly higher $(p \leq 0.05)$ than those obtained by the cut treatment ( 15.25 and $18.67 \mathrm{~N}$ at 25 and $60^{\circ} \mathrm{C}$, respectively)
(Figure 1B). No significant difference $(p \leq 0.05)$ was found by the effect of the mixing temperature of 25 and $60^{\circ} \mathrm{C}$. The incorporation of $0.5 \%$ of microbial TGase allowed increasing hardness values in both treatments (Figures 1A,B). Microbial transglutaminase (MTGase) is a calcium-independent enzyme, which can be obtained from Streptoverticillium ladakanum or Streptoverticillium mobaraense. This enzyme catalyzes an acyl transfer reaction between $\gamma$-carboxiamide groups of glutaminyl residues in proteins. When the primary amine is the $\varepsilon$-amino group of lysine and lysil residues, $\varepsilon$-( $\gamma$-glutamyl) lysine crosslinking is formed. The enzyme is commercially used to improve the gelling capacity of different meat proteins (13). The effect was significantly higher $(p \leq 0.05)$ on gels obtained by mixing and subjected to $60^{\circ} \mathrm{C}$, with hardness values of $76.25 \mathrm{~N}$. In cut gels, MTGase improved hardness when cutting at $25^{\circ} \mathrm{C}$, although, at $60^{\circ} \mathrm{C}$ the enzyme had no effect. Cooked crab meat forms weak gels if soluble proteins are not extracted by washing or pressing $(6,7)$. Cooked meat from Chinese mitten crab (Eriocheir sinensis) 

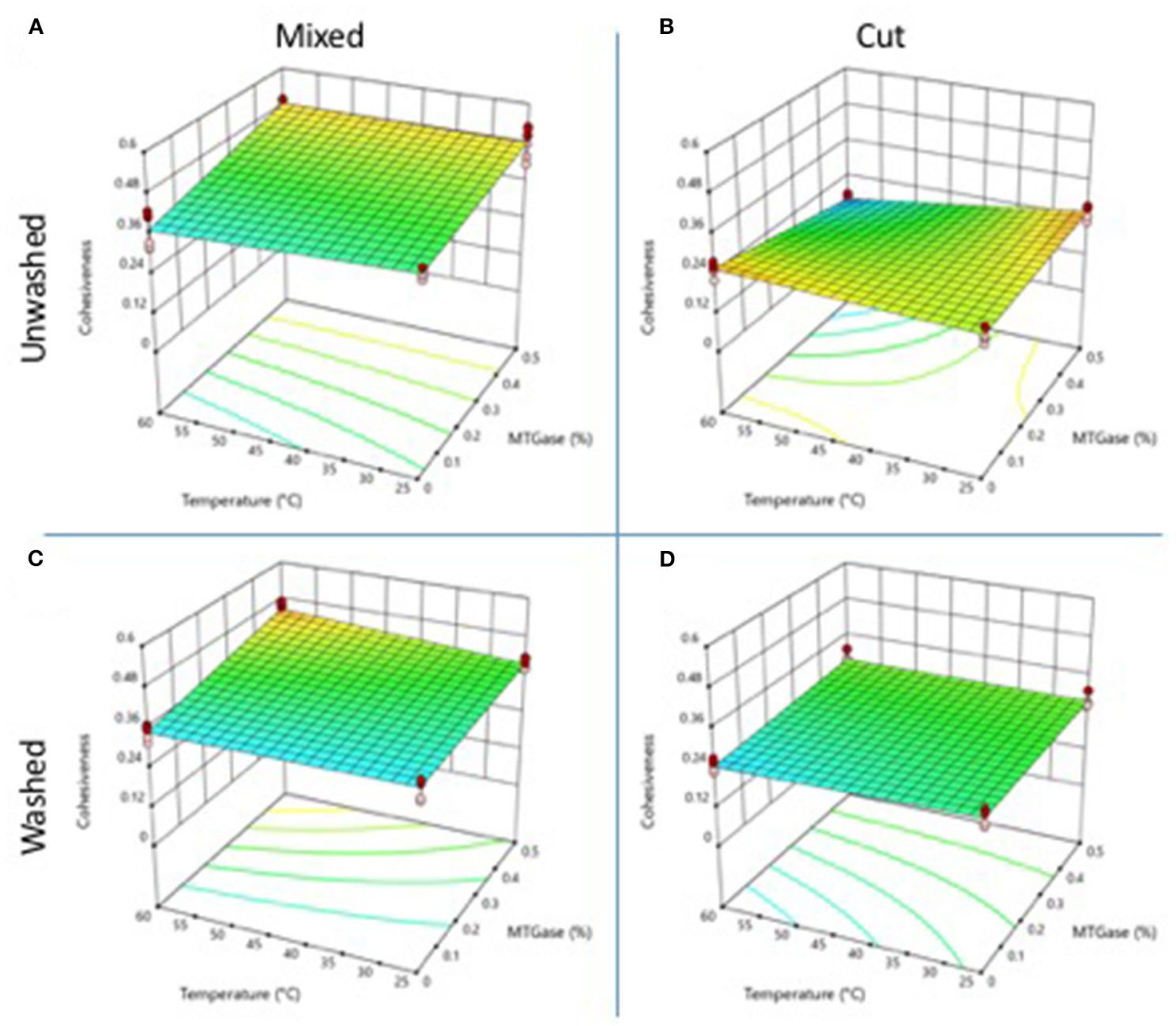

FIGURE 2 | Changes in gel cohesiveness properties as a function of the type and temperature mixing method, washing of the cooked meat, and adding of microbial MTGase. (A) Mixed-unwashed samples, (B) Cut-unwashed samples, (C) Mixed-washed samples, and (D) Cut-washed samples.

decreased the mechanical properties of surimi gels when added at 10-30\% into surimi gels (14). Mechanical properties of gels from cooked crab meat, obtained by the cutting process, increased by incubating them at $40^{\circ} \mathrm{C}$ for $30 \mathrm{~min}$ with MTGase before cooking at $90^{\circ} \mathrm{C}(8)$. In this work, cooked crab meat showed high hardness values just by mixing the whole muscle fibers (without cutting) at $60^{\circ} \mathrm{C}$ before cooking directly at $90^{\circ} \mathrm{C}$ without previous incubation.

The gels obtained by washing the cooked meat with cold water, to remove the water-soluble protein partially, had higher hardness values than those obtained from unwashed meat (Figure 1). Control gels obtained without MTGase, using the mixing technique (Figure 1C), had higher hardness values than those of gels obtained by cutting. In both processes (mixed and cut) no significant difference $(p \leq 0.05)$ was found by processing temperature (Figures 1C,D). The addition of MTGase increased the hardness value in all gels. The gels obtained by mixing at $60^{\circ} \mathrm{C}$ had the highest hardness value $(88.60 \mathrm{~N})$.
Washing the cooked crab meat three times increases the mechanical properties of the gels but also eliminates the distinctive odor and flavor from crab. The addition of MTGase to washed cooked crab meat significantly improves the final texture (8). It is possible to apply a single wash cycle to the crab meat and combine it with MTGase to improve the mechanical properties, however, the obtained gels are weak and do not have the same textural properties as the commercial restructured products (3).

\section{Cohesiveness}

Figure 2 shows the cohesiveness of gels obtained from cooked crab meat. The gels obtained by mixing (Figure 2A) had significantly higher values $(p<0.05)$ than the gels obtained by cutting (Figure 2B). The gels obtained by mixing, with no MTGase, showed a cohesiveness value of 0.40 at $25^{\circ} \mathrm{C}$ and 0.40 at $60^{\circ} \mathrm{C}$. In gels obtained by cutting, the cohesiveness was 0.23 and 0.25 for 25 and $60{ }^{\circ} \mathrm{C}$, respectively. The low cohesiveness values in gels obtained by cutting indicate that the sample lost 

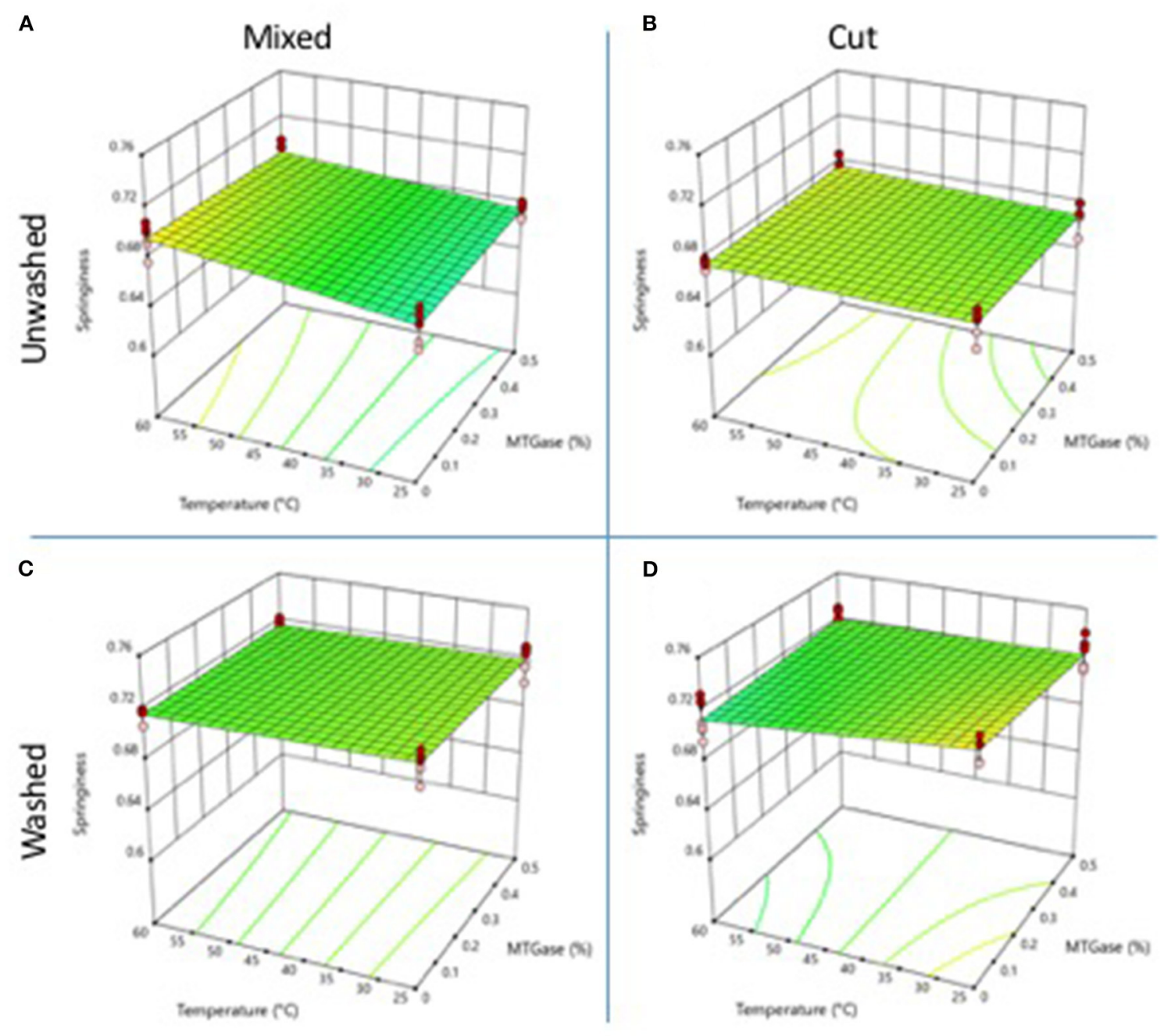

FIGURE 3 | Changes in gel springiness properties as a function of the type and temperature mixing method, washing of the cooked meat, and adding of microbial MTGase. (A) Mixed-unwashed samples, (B) Cut-unwashed samples, (C) Mixed-washed samples, and (D) Cut-washed samples.

its internal structure during the first compression, so it did not require much force to compress it again. In gels obtained by mixing, the presence of the fibers of the crab muscle induced a more cohesive structure. The addition of MTGase allowed increasing the cohesiveness values. The gels obtained by mixing at $25^{\circ} \mathrm{C}$ had a value of 0.48 , while, in gels processed at $60^{\circ} \mathrm{C}$, it was 0.54 . In gels prepared by cutting, no effect of MTGase was observed, with cohesiveness values of 0.23 and 0.16 at 25 and $60^{\circ} \mathrm{C}$, respectively. Washing with cold water did not have much effect on cohesiveness values (Figures 2C,D). Gels from unwashed cooked crab meat, obtained with $0.5 \%$ MTGase and mixed at $60^{\circ} \mathrm{C}$, showed the highest cohesiveness values.

\section{Springiness}

The springiness of the gels was not significantly affected ( $p \leq$ 0.05 ), by none of the treatments (Figure 3). Springiness values ranged from 0.67 to 0.68 in gels obtained from unwashed meat (Figures 3A,B). The gels obtained from cooked and washed meat had slightly higher springiness values (Figures 3C,D), ranging from 0.71 to 0.72 , although, this difference was not significant ( $p$ $<0.05)$. Springiness is a texture parameter that usually remains at intermediate values and is not modified by washing or the use of MTGase (3). In the present work, this parameter was neither increased nor diminished by the mixing technique.

\section{Chewiness}

Chewiness represents the energy required to chew a solid food and disintegrate it to swallow it. Figure 4 shows the chewiness values. Gels obtained from cut crab meat (Figures 4B,D) showed lower values of chewiness than gels from mixed crab meat.

The mixing temperature $\left(25\right.$ or $\left.60^{\circ} \mathrm{C}\right)$ did not significantly change $(p \leq 0.05)$ the chewiness of gels obtained from unwashed and MTGase-free cooked crab meat, presenting values of 31.35 and $27.77 \mathrm{~N} \mathrm{~cm}$, respectively. The gels obtained by the cutting process, showed lower chewiness values $(p \leq 0.05)$ than those of mixing, being 5.29 and $7.14 \mathrm{~N} \mathrm{~cm}$, respectively. 

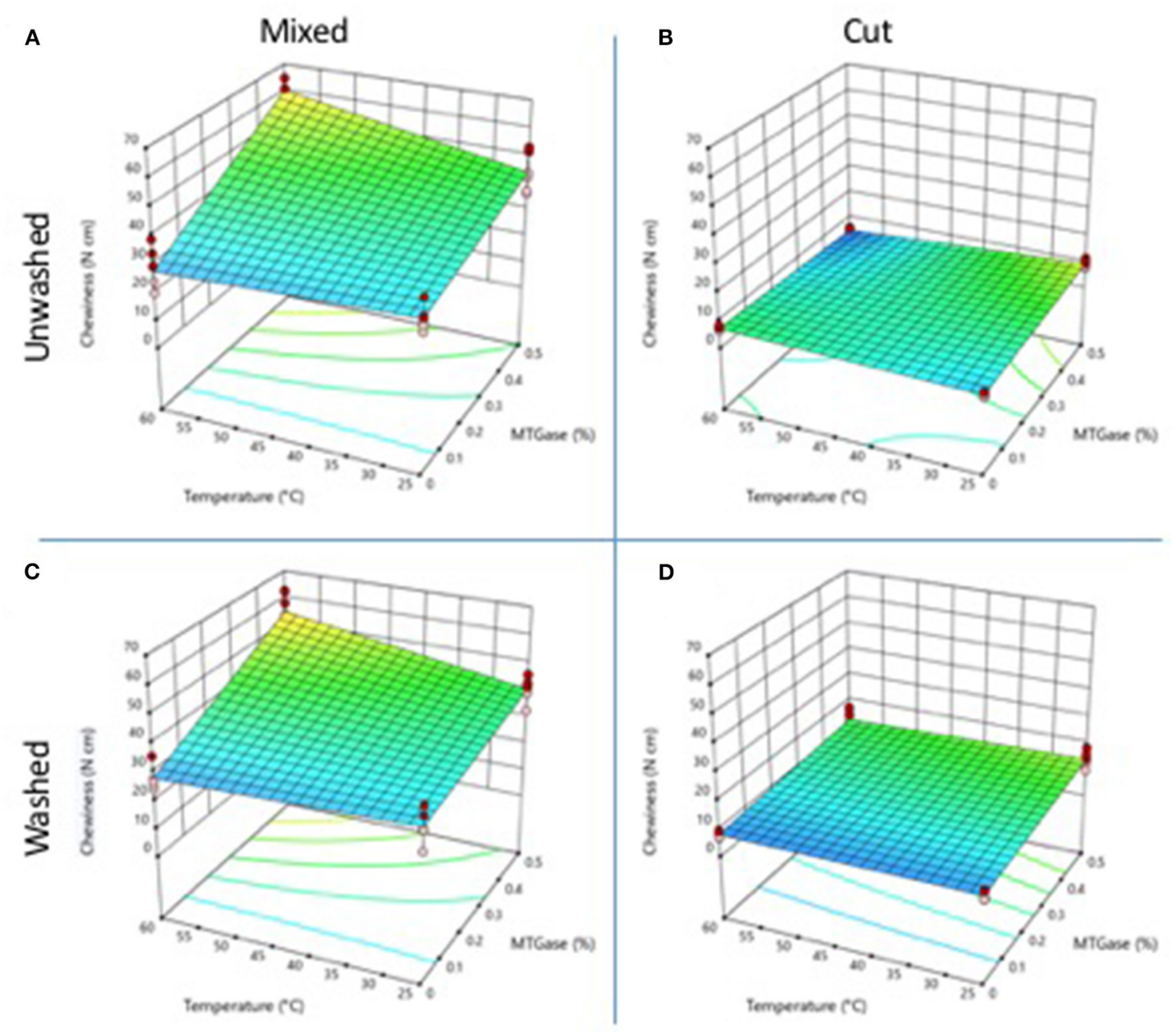

FIGURE 4 | Changes in gel chewiness properties as a function of the type and temperature mixing method, washing of the cooked meat, and adding of microbial MTGase. (A) Mixed-unwashed samples, (B) Cut-unwashed samples, (C) Mixed-washed samples, and (D) Cut-washed samples.

The addition of $0.5 \%$ MTGase increased the chewiness of the gels obtained by mixing, but not in the gels obtained by cutting. The effect was higher on gels obtained from unwashed crab meat, at $60^{\circ} \mathrm{C}$, reaching a value of 60.02 $\mathrm{Ncm}$ (Figure 4A). This value was slightly higher than that of gels obtained by cutting $(54.62 \mathrm{~N})$ at the same temperature with washed cooked meat (Figure 4C). The chewiness is a textural parameter that is favored by the addition of MTGase under incubation conditions, in which the enzyme is allowed interacting and forming covalent bonds between adjacent protein chains (9). In the present work, even without incubation, MTGase improved the chewiness of gels obtained by mixing at $60^{\circ} \mathrm{C}$.

\section{Extractable Water}

Extractable water content (EW) is inversely associated with water holding capacity (WHC). Low values of extractable water mean high WHC. Gels obtained from unwashed meat, by the mixing method with no MTGase, showed EW values of 25.48 and $30.11 \%$ at 25 and $60^{\circ} \mathrm{C}$, respectively (Figure $5 \mathbf{A}$ ); while gels obtained by the cutting process (Figure 5B) had higher EW values of 32.15 and $35.52 \%$ for 25 and $60^{\circ} \mathrm{C}$, respectively. The addition of $0.5 \%$ of MTGase increased the value of $\mathrm{EW}$ in gels mixed at $25^{\circ} \mathrm{C}(37.57 \%)$ but not in the gels prepared by mixing at $60^{\circ} \mathrm{C}$. In gels obtained by the cutting process, the addition of $0.5 \%$ of MTGase decreased significantly $(p \leq 0.05)$ the EW values at both temperatures.

Gels obtained from meat washed with cold water, by mixing at $60^{\circ} \mathrm{C}$ with no MTGase, presented lower values of EW than gels processed at $25^{\circ} \mathrm{C}$ (Figure $5 \mathrm{C}$ ). The addition of $0.5 \%$ of MTGase resulted in higher values of EW. The gels obtained by cutting had higher EW values than those of gels obtained by mixing (Figure 5D). Gels obtained by mixing or cutting showed EW $>25 \%$, indicating that additional strategies are required to improve the water holding capacity, such as the use of gums, 

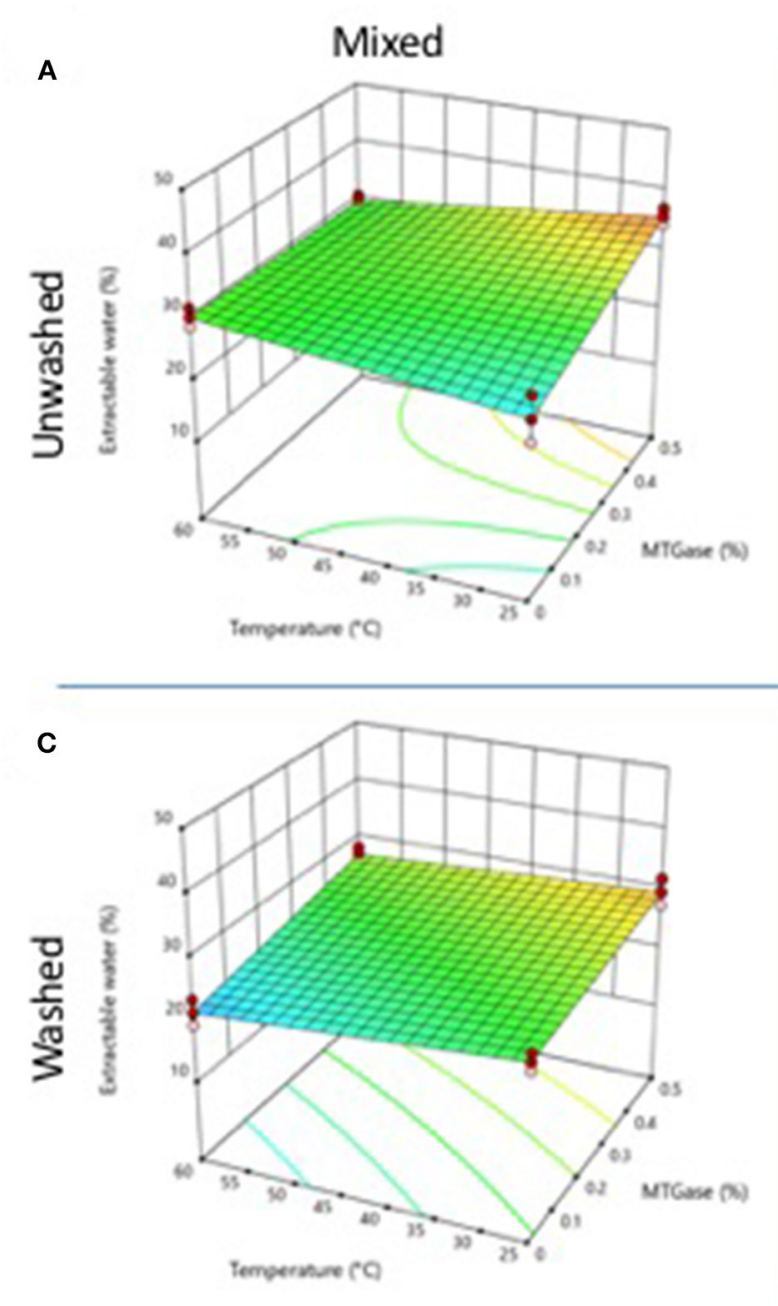

B
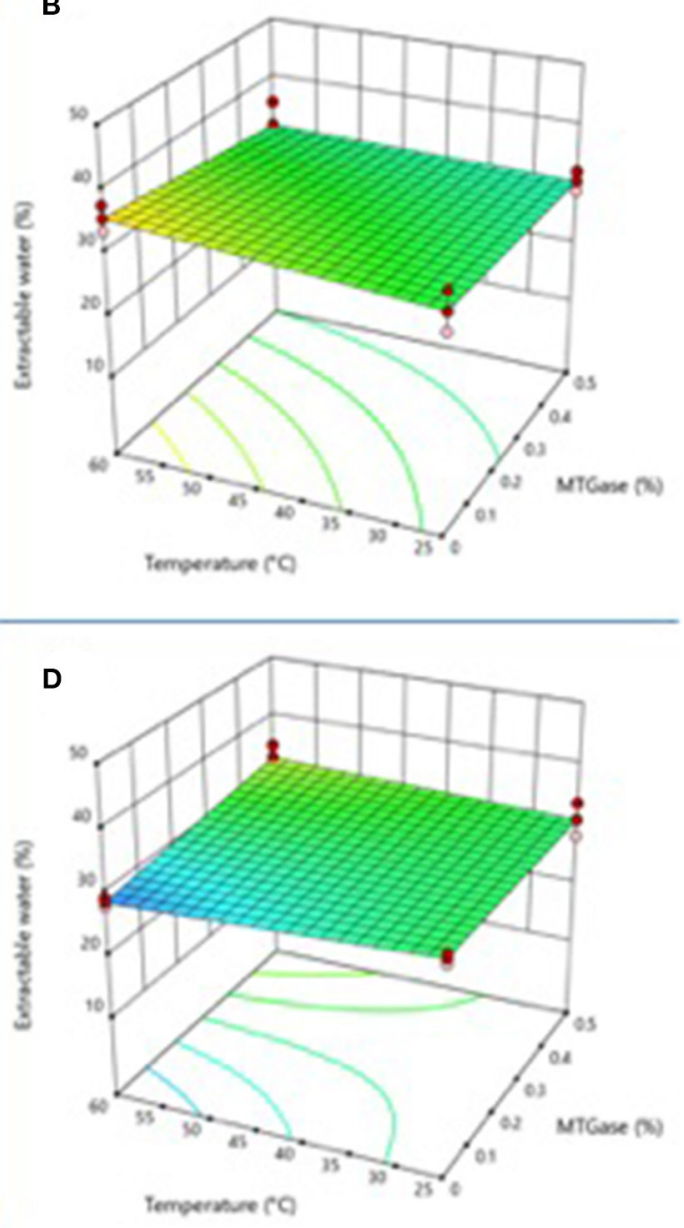

FIGURE 5 | Changes in gel extractable water properties as a function of the type and temperature mixing method, washing of the cooked meat, and adding of MTGase. (A) Mixed-unwashed samples, (B) Cut-unwashed samples, (C) Mixed-washed samples, and (D) Cut-washed samples.

starches, or other hydrocolloids. High levels of EW have been previously reported in gels obtained from cooked crab meat $(7,8)$.

\section{Color Attributes}

Table 1A shows the changes in color of unwashed cooked crab meat gels. In gels obtained without MTGase and by mixing process, the luminosity values (L) were 74.6 and 74.1, Chroma (C) of 4.8 and 4.5, and Hue $(\mathrm{H})$ of 130.7 and 125.8 at 25 and $60^{\circ} \mathrm{C}$, respectively. These values are located at the grayishgreen hue region of the color scale. Gels obtained by the cutting process showed $\mathrm{L}^{*}$ values of 80.03 and $77.78, \mathrm{C}^{*}$ values of 4.3 and $4.5, \mathrm{H}^{*}$ of 74.49 and 83.3 at 25 and $60^{\circ} \mathrm{C}$, respectively. These values correspond to grayish-yellow hues. Crab meat gels from cooked meat with $0.5 \%$ MTGase prepared by mixing had values similar to those obtained in enzyme-free treatments: 75.9 and 74.0 for $\mathrm{L}^{*}, 5.2$, and 4.5 for $\mathrm{C}^{*}$ and 123.6 and 125.5 for $\mathrm{H}^{*}$, at 25 and $60^{\circ} \mathrm{C}$, respectively. These values correspond to grayish-yellow hue region. The gels obtained from washed meat had color attributes very similar to gels obtained from unwashed meat (Table 1B). The small changes in color attributes might be because the crab meat is pale, not intense, and was only washed with cold water, which prevented the extraction of several compounds responsible for the color.

\section{Gelling Improving}

Crabs require to be steamed or boiled to separate the meat from the shell. The cooking operation affects the functional properties of crab meat limiting its use to produce restructured products. A few studies have recently proposed extracting the soluble proteins by centrifugation $(6,7)$ or by a washing process, like those used in surimi technology, to improve the gelling capacity (8). Still, such processes negatively affect the unique flavor of crab, which is highly demanded by consumers. Using of MTGase has been proposed to improve the mechanical properties of protein gels from cooked crab meat, allowing reducing from 
TABLE 1 | Changes in color attributes of gels by the effect of the type and temperature mixing method, washing of the cooked meat and adding of microbial TGase.

\begin{tabular}{|c|c|c|c|c|c|c|c|c|}
\hline \multirow{2}{*}{$\begin{array}{l}\text { Color } \\
\text { atribute }\end{array}$} & \multicolumn{4}{|c|}{$25^{\circ} \mathrm{C}$} & \multicolumn{4}{|c|}{$60^{\circ} \mathrm{C}$} \\
\hline & Mixed & Cut & Mixed & Cut & Mixed & Cut & Mixed & Cut \\
\hline \multicolumn{9}{|c|}{ (A) Gels from unwashed cooked crab meat } \\
\hline$L^{*}$ & $74.6 \pm 1.4^{a}$ & $76 \pm 0.8^{a}$ & $75 \pm 1.1^{\mathrm{a}}$ & $75.9 \pm 1.1^{\mathrm{a}}$ & $74.1 \pm 0.9^{a}$ & $75.6 \pm 0.6^{a}$ & $74 \pm 1^{\mathrm{a}}$ & $75 \pm 1.1^{\mathrm{a}}$ \\
\hline$a^{*}$ & $-3.2 \pm 0.8^{a}$ & $-1.9 \pm 0.1^{b}$ & $-2.9 \pm 0.7^{\mathrm{a}}$ & $-1.9 \pm 0.3^{a}$ & $-2.6 \pm 0.3^{\mathrm{a}}$ & $-2 \pm 0.8^{a}$ & $-2.6 \pm 0.7^{\mathrm{a}}$ & $-3.4 \pm 0.3^{a}$ \\
\hline $\mathrm{C}^{*}$ & $4.8 \pm 0.4^{a}$ & $4.7 \pm 0.2^{b}$ & $5.2 \pm 0.9^{a}$ & $4.8 \pm 0.3^{a}$ & $4.5 \pm 0.5^{a}$ & $4.6 \pm 0.9^{a}$ & $4.5 \pm 0.7^{a}$ & $5.9 \pm 1.4^{\mathrm{a}}$ \\
\hline $\mathrm{H}^{*}$ & $130.7 \pm 8.8^{\mathrm{a}}$ & $113.6 \pm 2.8^{b}$ & $123.6 \pm 4.8^{\mathrm{a}}$ & $113.9 \pm 3.5^{b}$ & $125.8 \pm 6.2^{\mathrm{a}}$ & $114.6 \pm 10^{a}$ & $125.8 \pm 0.7^{a}$ & $124.2 \pm 11.1^{\mathrm{a}}$ \\
\hline Whitness & $74.2 \pm 1.4^{\mathrm{a}}$ & $75.5 \pm 0.8^{a}$ & $75.3 \pm 1.3^{\mathrm{a}}$ & $76 \pm 0.8^{a}$ & $73.7 \pm 1.2^{\mathrm{a}}$ & $75.1 \pm 0.5^{a}$ & $73.6 \pm 0.9^{a}$ & $74.3 \pm 1.2^{\mathrm{a}}$ \\
\hline \multicolumn{9}{|c|}{ (B) Gels from washed cooked crab meat } \\
\hline$L^{*}$ & $77.2 \pm 1.9^{a}$ & $80 \pm 0.5^{b}$ & $77.6 \pm 2.4^{\mathrm{a}}$ & $80.2 \pm 1.3^{a}$ & $75 \pm 0.9^{a}$ & $77.7 \pm 0.4^{b}$ & $77 \pm 0.7^{a}$ & $78.2 \pm 0.7^{\mathrm{a}}$ \\
\hline Whitness & $77 \pm 1.8^{a}$ & $79.5 \pm 0.5^{b}$ & $77.4 \pm 2.3^{\mathrm{a}}$ & $79.7 \pm 1.1^{\mathrm{a}}$ & $74.8 \pm 3.4^{a}$ & $77.3 \pm 0.4^{a}$ & $76.6 \pm 0.7^{a}$ & $77.7 \pm 0.6^{a}$ \\
\hline
\end{tabular}

${ }^{a, b}$ Different letters indicate differences $(P<0.05)$ between treatment (mixed or cut) for each measured property. Values indicate the means and its respective standard deviations.

three to only one the number of washing cycles needed to extract the soluble proteins, but the flavor of crab meat is affected (3). For the first time, this work proposes a novel but straightforward technique to improve the mechanical properties of gels obtained from cooked crab meat proteins. The mentioned process involves only mixing the cooked meat fibers of crab at a mild temperature to induce denaturation of proteins and obtaining a better protein network strengthened by the action of MTGase. This inner network allows obtaining gels with appropriated gelling properties and preserving the distinctive flavor of the crab. The process is simple, of low cost, technically feasible, and easy to implement. Although, MTGase decreases the water holding capacity, adding gums or starches which are extensively used in restructured products, may improve this functional property with a low adverse effect on texture or flavor.

\section{CONCLUSIONS}

Mixing the cooked crab meat, in the absence of salt, for a short time, allowed obtaining meat paste that, when formatted

\section{REFERENCES}

1. Haefner PA. The Biology and Exploitation of Crabs. Economic Aspects: Fisheries and Culture. Orlando, FL: Academic Press Inc. (1985). doi: 10.1016/B978-0-12-106410-5.50012-2

2. FAO. The State of World Fisheries and Aquaculture. Opportunities and Challenges (2014). Available online at: http://www.fao.org/3/a-i3720e.pdf (accessed January 7, 2020).

3. Martínez-Maldonado MA, Ramírez-De León JA, Méndez-Montealvo MG, Morales-Sánchez E, Velazquez G. Effect of the cooking process on and heated at $90^{\circ} \mathrm{C}$ induced the formation of gels with textural properties suitable for a restructured product. The addition of MTGase at $0.5 \%$ allowed increasing the mechanical properties, but decreased water holding capacity. The proposed method of mixing cooked crab meat fibers, unlike the traditionally reported cutting method, offers an alternative for producing restructured products from crustaceans, which require a previous cooking resulting in poor textural properties when using traditional techniques. The technique reported in this work offers a feasible alternative to process and commercialize crab meat.

\section{DATA AVAILABILITY STATEMENT}

The original contributions presented in the study are included in the article/supplementary materials, further inquiries can be directed to the corresponding author/s.

\section{AUTHOR CONTRIBUTIONS}

All authors listed have made a substantial, direct and intellectual contribution to the work, and approved it for publication. crab (Callinectes sapidus). J Aquat Food Prod Technol. (2018) 27:41829. doi: 10.1080/10498850.2018.1447060

4. Téllez-Luis SJ, Uresti RM, Ramírez JA, Vázquez M. Low-salt restructured fish products using microbial transglutaminase. J Food Sci Agric. (2002) 82:953-9. doi: 10.1002/jsfa.1132

5. Uresti RM, Velazquez G, Vázquez M, Ramírez JA, Torres JA. Effect of sugars and polyols on the functional and mechanical properties of pressure-treated arrowtooth flounder (Atheresthes stomias) proteins. Food Hydrocoll. (2005) 19:964-73. doi: 10.1016/j.foodhyd.2004.12.006 
6. Baxter SR, Skonberg DI. Thermal gelation of previously cooked minced meat from jonah crab (Cancer borealis). J Food Sci. (2006) 1:499503. doi: 10.1111/j.1750-3841.2006.00154.x

7. Baxter SR, Skonberg DI. Gelation properties of previously cooked minced meat from Jonah crab (Cancer borealis) as affected by washing treatment and salt concentra-tion. Food Chem. (2008) 109:332-9. doi: 10.1016/j.foodchem.2007.12.044

8. Martínez MA, Robledo V, Velázquez G, Ramírez JA, Vázquez M, Uresti RM. Effect of precooking temperature and microbial transglutaminase on the gelling properties of blue crab (Callinectes sapidus) proteins. Food Hydrocoll. (2014) 35:264-9. doi: 10.1016/j.foodhyd.2013.06.001

9. Hernández-Robledo V, Uresti RM, Martinez MM, Velázquez G. Efecto de la Transglutaminasa Microbiana Sobre las Propiedades Mecánicas de Geles de Carne de Jaiba Cocida. Ciudad Victoria: Ciencia UAT (2015). doi: 10.29059/cienciauat.v10i1.751

10. Hernández-Robledo V, Martínez Maldonado MÁ, Uresti-Marín RM, Ramírez JA, Velázquez G. Effect of washing treatment and microbial transglutaminase on the gelling properties of blue crab (Callinectes sapidus) proteins. CyTA-J Food. (2017) 15:165-70. doi: 10.1080/19476337.2016.1156771

11. Uresti RM, Velazquez G, Vázquez $M$, Ramírez JA, Torres JA. Restructured products from arrowtooth flounder (Atheresthes stomias) using high-pressure treatments. Eur Food Res Technol. (2005) 220:113-9. doi: 10.1007/s00217-004-1026-y

12. Martínez-Maldonado MA, Velazquez G, de León JAR, Borderías AJ, Moreno HM. Effect of high pressure processing on heat-induced gelling capacity of blue crab (Callinectes sapidus) meat. Innovat Food Sci Emerg Technol. (2020) 59:102253. doi: 10.1016/j.ifset.2019.102253
13. Ramírez J, Uresti $\mathrm{R}$, Téllez $\mathrm{S}$, Vázquez $\mathrm{M}$. Using salt and microbial transglutaminase as binding agents in restructured fish products resembling hams. J Food Sci. (2002) 67:1778-4. doi: 10.1111/j.1365-2621.2002.tb08722.x

14. Liang F, Lin L, He T, Zhou X, Jiang S, Lu J. Effect of transglutaminase on gel properties of surimi and precocious Chinese mitten crab (Eriocheir sinensis) meat. Food Hydrocolloids. (2020) 98:105261. doi: 10.1016/j.foodhyd.2019.105261

Conflict of Interest: The authors declare that the research was conducted in the absence of any commercial or financial relationships that could be construed as a potential conflict of interest.

Publisher's Note: All claims expressed in this article are solely those of the authors and do not necessarily represent those of their affiliated organizations, or those of the publisher, the editors and the reviewers. Any product that may be evaluated in this article, or claim that may be made by its manufacturer, is not guaranteed or endorsed by the publisher.

Copyright (c) 2021 Trejo-Díaz, Martínez-Maldonado, Uresti-Marín, Velazquez and Ramirez. This is an open-access article distributed under the terms of the Creative Commons Attribution License (CC BY). The use, distribution or reproduction in other forums is permitted, provided the original author(s) and the copyright owner(s) are credited and that the original publication in this journal is cited, in accordance with accepted academic practice. No use, distribution or reproduction is permitted which does not comply with these terms. 